\title{
The physiological functions of IKKs-selective substrate identification and their critical roles in diseases
}

\author{
Jian-shuai $\mathrm{YU}^{1,2}$, Jin $\mathrm{JIN}^{2,3,{ }^{*}}$, Yi-yuan $L I^{1, *}$ \\ ${ }^{1}$ Key Laboratory for Developmental Genes and Human Disease, Ministry of Education, Institute of Life Sciences, Jiangsu Province High-Tech Key \\ Laboratory for Bio-Medical Research, Southeast University, Nanjing 210096, China. \\ ${ }^{2}$ MOE Laboratory of Biosystem Homeostasis and Protection, and Life Sciences Institute, Zhejiang University, Hangzhou 310058, China. \\ ${ }^{3}$ Sir Run Run Shaw Hospital, College of Medicine Zhejiang University, Hangzhou 310016, China.
}

*Correspondence: liyiyuan@zju.edu.cn; jjin4@zju.edu.cn

https://doi.org/10.37175/stemedicine.v1i4.49

\begin{abstract}
The nuclear factor $\mathrm{KB}(\mathrm{NF}-\mathrm{kB})$ transcription factors exert central hub functions in multiple physiological processes including immune response, cell survival, proliferation and cytokine production, which has naturally become the core of research almost in all aspects of biomedical science over 30 years. Since both the activation and termination of NF-KB pathway are tightly regulated, little alteration can lead to excessive inflammatory responses and even result in tissue damage and severe diseases. The inhibitor of nuclear factor kappa-B (IKB) kinase (IKK) complex is the main regulator of the NF-KB signaling pathway, they mediate and deliver signals through phosphorylating certain substrates. In recent years, increased proteins have been identified to be targeted by IKK members and the particular modification mechanism becomes clear with the development of detecting techniques and structural biology. In this review, we summarize the known substrates of IKK family members either relevant or irrelevant to NF-KB signaling, their structures and phosphorylation patterns, and the related physiologic and/or pathologic responses. Understanding the regulation of IKKs on their substrates may be helpful to connect IKKs with specific signaling pathways or physiological phenomena, and is essential for targeting IKKs in clinical research.
\end{abstract}

Keywords: NF-KB $\cdot$ IKKs $\cdot$ Substrates $\cdot$ Immune response $\cdot$ Disease

\section{Brief introduction of NF- $\mathrm{KB}$ pathway and IKK families}

The nuclear factor $\kappa \mathrm{B}(\mathrm{NF}-\mathrm{kB})$ family of transcription factors are structurally homologues that include NF- $\mathrm{KB} 1$ p50, NF-кB2 p52, RELA p65, RELB and c-REL, which exist inactive in the cytoplasm in a complex combined with members of the inhibitor of $\kappa B$ (IкB) family $(1,2)$. In response to multiple stimuli including numerous mediators in immune systems like tumor necrosis factor (TNF), lipopolysaccharide (LPS), interleukin-1 (IL-1) or $\mathrm{T}$ cell activators (3), IкB kinase (IKK) complex mediates $\mathrm{NF}-\mathrm{\kappa B}$ activating process by directly phosphorylating $\mathrm{I} \kappa \mathrm{B}$, targeting it for proteasomal degradation (4). When released into the nucleus, $\mathrm{NF}-\kappa \mathrm{B}$ proteins regulate

Received: May 13, 2020; Accepted: Aug 9, 2020.

(c) The Author(s). 2020 This is an Open Access article distributed under the terms of the Creative Commons License (http://creativecommons.org/licenses/by/4.0/) which permits unrestricted use, distribution, and reproduction in any medium or format, provided the original work is properly cited. the expression of a large spectrum of genes encoding transcription factors, cytokines, adhesion molecules and immunoreceptors, thus to be essential for cell proliferation and survival, innate and adapt immune response and inflammation (5).

Signal-induced activation of NF- $\kappa B$ pathway demands specific phosphorylation of IKB proteins at Ser32 and Ser36 through the canonical IKK-dependent pathway (6). This IKK complex consists of two catalytic subunits IKK $\alpha$ and IKK $\beta$, together with the regulatory subunit NF- $\mathrm{KB}$ essential modulator NEMO (also called IKK $\gamma$ ) $(7,8)$. The $85 \mathrm{kDa}$ IKK $\alpha$ (previously known as CHUK), containing a protein kinase domain at its N-terminal half, and an elongated $\alpha$-helical scaffold/dimerization domain (SDD) and a NEMO binding domain (NBD) at its C-terminal, is identified first by yeast two-hybrid screen for NF- $\mathrm{kB}$ inducing kinase (NIK)-interacting proteins in $1997(9,10)$ (Figure 1).

By searching for IKK $\alpha$-related kinases with an expressed sequence tag (EST) on NCBI database, the second 
component of the IKK complex is cloned and designated $\operatorname{IKK} \beta$ (11). Overall, the two subunits are $52 \%$ identical, while their kinase domain exhibit $65 \%$ identity (12). Both of their kinase domains have two serine residues (Ser176, Ser180 for IKK $\alpha$ and Ser177, Ser181 for IKK $\beta)$, whose phosphorylation are required for the kinase functions $(13,14)$. A great structure difference between IKK $\alpha$ and IKK $\beta$ locates in their ubiquitin-like domain. IKK $\beta$ contains a key leucine at position 353 which is critical for IKK $\beta$ induced NF- $\kappa \mathrm{B}$ activation, while deleting the equivalent region on IKK $\alpha$ has no impact on its activities (15). Moreover, there is a putative nuclear localization signal on IKK $\alpha$ but not IKK $\beta$, which possibly contributes to the reported functions of IKK $\alpha$ in the nucleus (16). Recent years, diverse combinations of the IKK components have gradually been observed, IKK $\alpha$ or IKK $\beta$ can respectively form homodimers either with or without the scaffold NEMO, however the predominant IKK complexes remain to be the 1:1:2 ratio combination of IKK $\alpha$-IKK $\beta$-NEMO $(4,17)$.

In addition to IKK $\alpha$ and IKK $\beta$, it has been reported that there exist two other non-canonical IKK-related kinases, TNF receptor-associated factor (TRAF) family memberassociated NF- $\mathrm{BB}$ activator (TANK)-binding kinase 1

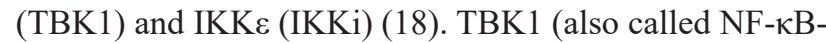
activating kinase NAK), was initially amplified by PCR with primers containing the same sequences to IKK $\alpha$ and IKK $\beta$, and was first identified by virtue of its interaction with TANK in a yeast two-hybrid screening $(19,20)$. IKK $\varepsilon$, which shares $64 \%$ homology to TBK1, was found by searching for proteins similar to IKK $\alpha$ and IKK $\beta$ in a database, and then isolated by using suppression subtractive hybridization technique in 1999 (21). These two kinases contain the same trimodular structure to IKK $\beta$ and the N-terminal catalytic domain of IKKE has approximate $30 \%$ similarity with that of IKK $\beta$ (22) (Figure 1). In contrast to the constitutive expression of IKK $\alpha$ and IKK $\beta$ in almost all cell types, the IKK $\varepsilon$ protein is primarily observed in immune cells, with the highest expression in the spleen (21). TBK1 and IKKE also form homodimers and heterodimers adopting the similar assembly of the canonical IKK subunits, which require a scaffold protein to efficiently target their substrates, whereas TANK, (NAK-associated protein 1) NAP1 and SINTBAD (similar to NAP1 TBK1 adaptor) seem to fulfill this function $(23,24)$. Using phosphopeptide mapping and site-specific mutagenesis, it has been found that phosphorylation on Ser172 in the kinase activation loop of TBK1 and IKKe should be necessary for the kinase activity (25).

In spite of the sequence similarities and presence in common complexes, IKK $\alpha$ and IKK $\beta$ or IKK $\varepsilon$ and TBK1 maintain distinct substrate specificities and largely nonoverlapping functions. Pro-inflammatory stimuli like TNF $\alpha$ and IL-1, or Toll-like receptor (TLR) ligands like LPS mainly activate IKK $\beta$ and NEMO for canonical NF- $\kappa \mathrm{B}$ pathway and innate immunity, whereas IKK $\alpha$ plays an ineffectual supporting role. In contrast, in response to CD40-ligand or B cellactivating factor (BAFF), IKK $\alpha$ primarily targets p 100 for processing and exhibits its kinase activity and function in adaptive immunity and lymphoid organ development $(26,27)$.

IKK $\varepsilon$ and TBK1 were initially described as NF$\kappa \mathrm{B}$ - and IKK-activating kinases, whereas it is already clear that they are also important mediators of antiviral responses by activating two other transcription factors, interferon regulatory factor 3 and 7 (IRF3 and IRF7) (2830). Additionally, TBK1 is reported to be involved in neuroinflammation and autoimmunity, and to be more essential than IKK $\varepsilon$ in the innate immune response (31).

In recent years, numerous substrates in addition to I $\kappa \mathrm{Bs}$ and various $\mathrm{NF}-\kappa \mathrm{B}$-independent functions of the IKK family have been discovered. These substrates and functions encompass signaling pathways regulating tumorigenesis, inflammation and cell cycle, and provide a bridge for crosstalk between IKK-related signaling cascades with critical diseases. This review focuses on the kinase activities of four IKK members, highlights some of the major substrates targeted by IKKs either NF- $\kappa$ B pathwaydependent or independent with the emphasis on the exact phosphorylation patterns and regulatory mechanisms. Understanding these post-translation modifications may shed light on exploitative capabilities of IKKs as effective therapeutic targets.

\section{Substrates identification by IKKs and its physiological functions \\ IKK $\alpha / I K K \beta$ mainly regulates canonical and alternative pathways of $\mathrm{NF}-\kappa \mathrm{B}$}

The pivotal function of the IKK complex is to phosphorylate I $\kappa \mathrm{B}$, including classical $\mathrm{I} \kappa \mathrm{B} \alpha, \mathrm{I} \kappa \mathrm{B} \beta$ and $\mathrm{I} \kappa \mathrm{B} \varepsilon$, and $\mathrm{NF}$ $\kappa \mathrm{B}$ precursors p105 and p100 (17) (Figure 2). These I $\mathrm{B}$ proteins share a tandem helical repeat motif called ankyrin repeat domain (ARD), which can functionally bind to the NF $-\kappa \mathrm{B}$ dimers (2). A structurally flexible PEST domain exists between their C-terminal and the ARD, and it is abundant in proline $(\mathrm{P})$, glutamic acid $(\mathrm{E})$, serine $(\mathrm{S})$ and threonine (T) (32). Besides, two critical serine residues on the $\mathrm{N}$-terminal of I $\kappa \mathrm{B} \alpha, \beta$ and $\varepsilon$ serve as phospho-acceptor sites during canonical NF- $\mathrm{kB}$ pathway activation (the exact sites are Ser32 and Ser36 on I $\kappa$ B $\alpha$, Ser19 and Ser23 on I $\mathrm{I} B \beta$, and Ser18 and Ser22 on $\mathrm{I} k \mathrm{~B} \varepsilon)(8,27,33)$. Via adaptors like TRAFs, a variety of membrane receptors activate the canonical NF- $\kappa B$ pathway. Once phosphorylated by IKK $\beta$, I $\kappa$ s are recognized and ubiquitinated by SCF/ $\beta$-TrCP E3 ubiquitin ligases, and then go through polyubiquitination and degradation $(34,35)$. Although IKK $\beta$ phosphorylates

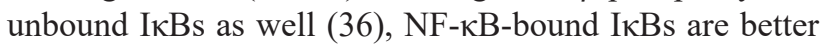
substrates for phosphorylation (37). The degradation of I $\kappa \mathrm{Bs}$ releases the restraint of $\mathrm{NF}-\kappa \mathrm{Bs}$, the free $\mathrm{NF}-\kappa \mathrm{Bs}$ thus go through nuclear transport and bind promoters of a wide range of target genes to function in numbers of NF$\kappa \mathrm{B}$-related cellular regulations.

As a non-classical IאB molecule, p105 is phosphorylated with the same mechanism as I $\mathrm{B} \alpha$. But in contrast to the rapidly phosphorylation of $\mathrm{I} \kappa \mathrm{B} \alpha$, IKK $\beta$ phosphorylates p105 with slow kinetics (38). In cells stimulated with NF$\kappa \mathrm{B}$-activating agents, IKK $\beta$ directly phosphorylates Ser927 


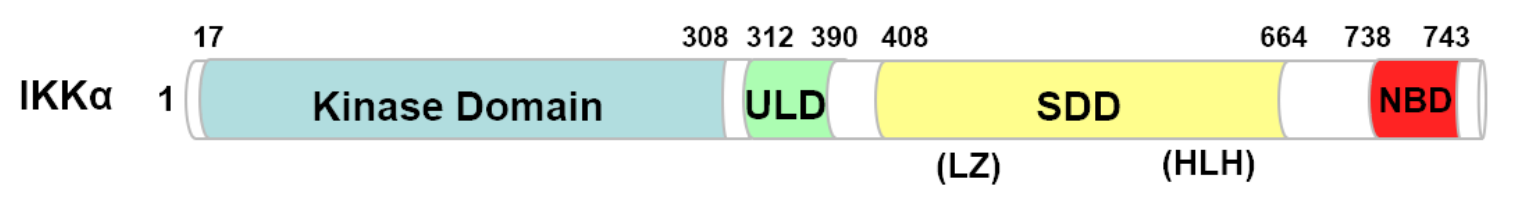

\section{(LZ) (HLH)}

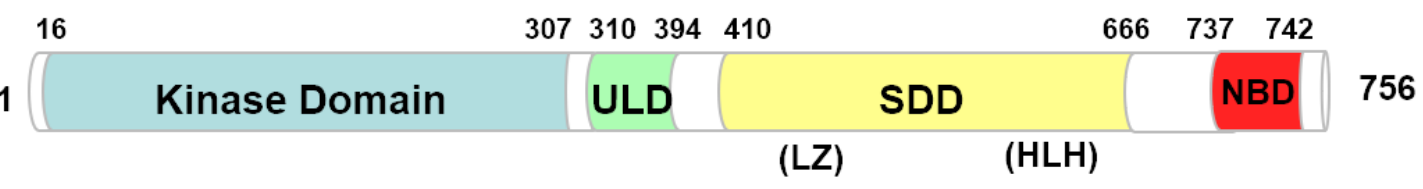
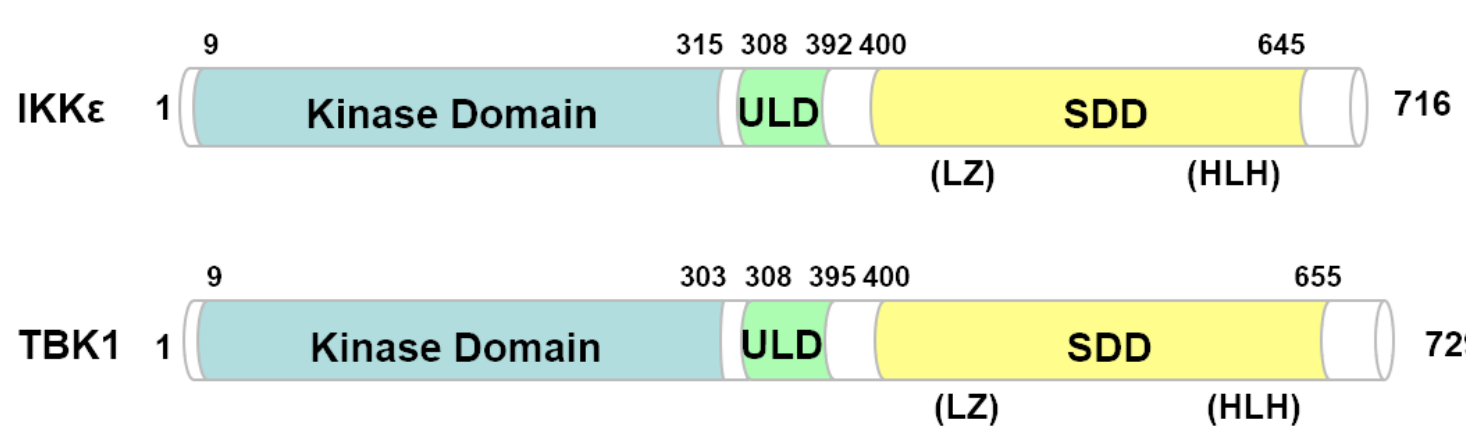

Figure 1. The structural comparison of the IKK family members. The principal structural motifs of the four members of IKB kinase (IKK) family are shown, together with amino acid numbers corresponding to the human proteins. ULD, ubiquitin-like domain; SDD, Scaffold dimerization domain; LZ, leucine-zipper; HLH, helix-loop-helix; NBD, NEMO-binding domain.

in the PEST domain of p105 causing degradation of p105 via the ubiquitin-dependent proteasome pathway, however not affecting the p105 processing $(39,40)$. Furthermore, a functional p105 death domain is reported necessary for recruitment of IKK, with an additional requirement of Ser932 phosphorylation on p105 proteolysis $(41,42)$. In addition, p105 is also found to form a complex with the MEK kinase TPL2 in some inactivated cells. Following the degradation of $\mathrm{p} 105$, the released TPL 2 activates the pro-proliferative mitogen-activated protein kinase (MAPK) signaling pathway (43). On the other hand, during the non-canonical NF- $\mathrm{KB}$ pathway activation, processing of p100 to generate p52 depends only on the IKK $\alpha$, neither IKK $\beta$ nor NEMO $(44,45)$. The processing pathway is triggered by different ligands, such as LT $\beta$ or BAFF, and further activated IKK $\alpha$ can phosphorylate Ser99, 108, 115, 123, 866 and 870 of p100, which leads to ubiquitination of $\mathrm{p} 100$ by $\mathrm{SCF} / \beta$-TrCP and then partial degradation of its ARD by proteasome $(46,47)$. Intriguingly, due to the slow activation kinetics of kinase NIK/IKK $\alpha$, the degradation of p100 is also a relatively slow process. Unlike the classical I $\kappa s$ which assemble with a single NF- $\mathrm{KB}$ dimer, p105 and p100 prefer to integrate two inhibitor proteins with at least two $N F-\kappa B$ molecules (48). Given the situation that p100 and p105 bind over half of cellular RelA, RelB and c-Rel, they could have profound impact on multiple NF- $\kappa \mathrm{B}-$ mediated cellular processes (49).

In addition to p105 and p100, the phosphorylation of p65 conducts in the similar signaling pathways. The N-terminal Rel homology region of p65 is responsible for its association with I $\kappa$ Bs and NF- $\kappa$ Bs, and also determines its nuclear localization and DNA binding, while the transcriptional activation domain (TAD) at C-terminal determines its function as an activator of transcription (2). Several serine residues on the p65 TAD have been identified as phosphorylation sites and are targeted by distinct signaling pathways, the most extensively studied are Ser536, 468 and 276 (50). It has been reported that either induced by LPS or TNF, the inactive p65 in the cytoplasm is phosphorylated on Ser536 by IKK $\beta$, and is dephosphorylated rapidly in the nucleus (51-53). The Ser536 phosphorylation by IKK $\beta$ is a key to potentiate p65 transcriptional activity, and it requires prior phosphorylation of I $\mathrm{B} \alpha$ at Ser32 and Ser36 as well as an intact NF- $\kappa \mathrm{B} / \mathrm{I} \kappa \mathrm{B} \alpha$ complex (54). Additionally, more recent reports have shown that Ser468 in TAD2 of p65 is also phosphorylated by IKK $\beta$, and moreover, IKK $\alpha$ is found capable of phosphorylating p65 and c-Rel, which shows an opposite function compared to IKK $\beta$. Directly phosphorylated by IKK $\alpha$ on C-terminal, p65 and c-Rel go through accelerated turnover followed by quick detachment from target genes, resulting in the termination of NF- $\kappa \mathrm{B}$-associated transcription of critical genes (55). These discoveries reveal that selective inhibition of IKK $\alpha$, which has little impact on $\mathrm{I} \kappa \mathrm{B} \alpha$, has remarkable effect on upregulating innate immunity by preventing the turnover of p65 and c-Rel, raising the novel therapeutic roles for IKK $\alpha$ inhibitors in the treatment of intricate infections.

Although no catalytic function of NEMO has been reported, this crucial regulatory component of the IKK complex is indispensable for signal-dependent activation of IKK $\beta$ (56). NEMO is comprised of a C-terminal zinc-finger region, a leucine-zipper and two coiled-coil domains. The N-terminal region of NEMO interacts with 


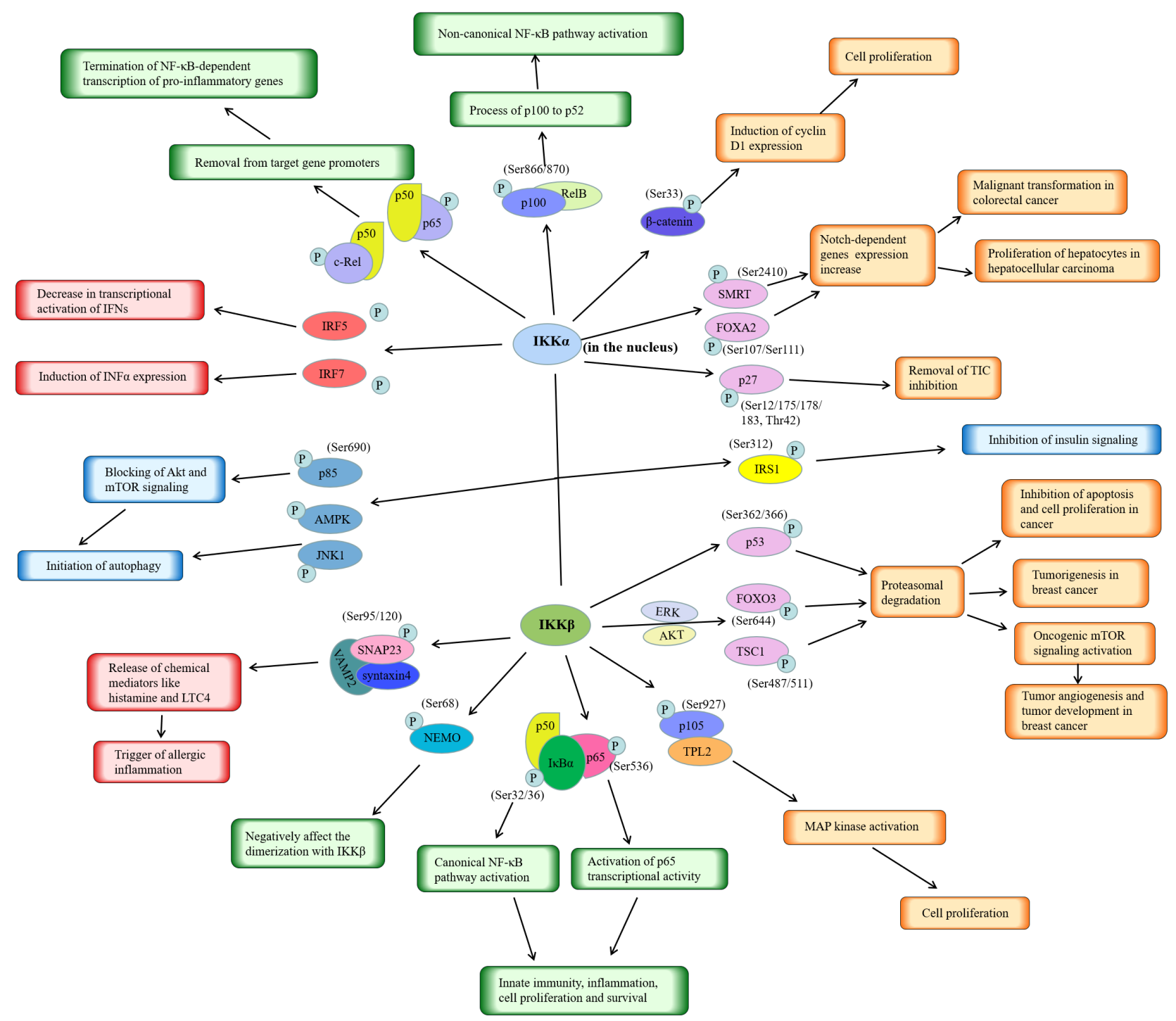

Figure 2. The substrates of IKKa and IKK $\beta$ and the related functions. In addition to activation of the canonical and non-canonical NF-KB pathways through phosphorylation of the IKBs, IKKa and IKK $\beta$ are now thought to phosphorylate a number of other substrates. And in turn, other than immune responses, IKKa and IKK $\beta$ are also important signaling proteins for critical cellular processes associated with several diseases like cancer. For more information see text.

the IKK's NBD which is essential for IKK activation (17). Multiple phosphorylation sites have been identified on NEMO, however the precise model and the underlying molecular mechanism contributing to IKK activation are missing until the phosphorylation of NEMO by IKK $\beta$ is found (57). In vitro, IKK $\beta$ phosphorylates NEMO at Ser43, Ser68 and Ser85 within IKK binding domain, while only Ser68 phosphorylation exhibits physiological functions in vivo. The NEMO phosphorylation at position Ser68, which is located in the interacting region with IKK $\beta$, has negative effect on NEMO's dimerization as well as the NEMO-IKK $\beta$ interaction, suggesting the negative regulatory function of phosphorylated NEMO upon the activation of the IKK complex and NF- $\mathrm{KB}$ (58).

\section{IKK $\beta$ phosphorylates tumor suppressors and promotes} tumorigenesis

It is worth mentioning that IKK $\beta$ is a commonly activated oncogenic kinase in human cancers. It has been reported that IKK $\beta$ phosphorylates several tumor suppressor proteins, among which the most remarkable one is p53 (Figure 2). p53 contains the same phosphorylation motif

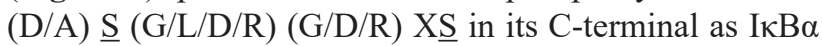
does, and indeed, IKK $\beta$ phosphorylates p53 at Ser362 and Ser366 within this motif. This DNA-damaging reagent-induced phosphorylation is recognized by $\beta$-TrCP-mediated ubiquitination and leads to proteasomal degradation of p53 (59). The resulting loss of p53 causes enhanced IKK $\beta$ activity and impairs the glucocorticoidsdependent repression of NF- $\mathrm{\kappa B}$ target gene transcription, and increases the rate of aerobic glycolysis $(60,61)$. Together, these findings suggest a positive-feedback loop exists during the IKK-NF- $\mathrm{kB}$ activation driven by glycolysis and provides evidence for the mechanism that tumor cells may damage normal inflammatory regulation in the tumor microenvironment. 
Another two tumor suppressor proteins, Forkhead O transcription factor 3 (FOXO3) and tuberous sclerosis complex 1 (TSC1) are also identified as substrates of IKK $\beta$. We have known that, FOXO3 can suppress tumor growth and tumor size in breast cancer (62). IKK $\beta$, together with AKT/protein kinase B and extracellular regulated protein kinase (ERK) which are commonly activated in human cancers, can phosphorylate FOXO3a in response to insulin stimulation and growth factor. Phosphorylation of FOXO3a by IKK $\beta$ occurs at Ser644, which triggers ubiquitination and subsequent proteolysis of FOXO3a. Such downregulation of FOXO3a in breast results in cell proliferation and tumorigenesis $(63,64)$.

A similarly interesting story is that, the TSC1/ TSC2 complex which acts as an inhibitor upstream of mammalian target of rapamycin (mTOR) pathway is also inactivated under the control of IKK $\beta$, AKT and ERK. In response to TNF, IL-1 $\beta$ or a cardiovascular homeostasis controller angiotensin II (Ang II), IKK $\beta$ mediates Ser487/ Ser511 phosphorylation of TSC1, accompanied by the phosphorylation of TSC2 by AKT and ERK. The phosphorylation results in the destruction of the TSC1/ TSC2 complex, and thus induces the oncogenic mTOR signaling, promotes tumor angiogenesis and ultimately leads to tumor development $(65,66)$. Furthermore, Ser511 phosphorylation of TSC1 is reported in multiple tumor types associated with vascular endothelial growth factor production, and is closely related to poor clinical outcomes in breast cancer (65).

Notably, in addition to IKK $\beta$, substrates regulated by IKK $\alpha$ also have crucial functions in a variety of inflammation-mediated tumorigenesis. The oncoprotein $\beta$-catenin and $\mathrm{I} \kappa \mathrm{Bs}$ are both phosphorylated at the similar N-terminal serines, and in normal situation regulated by IKK $\beta$, $\beta$-catenin is subsequently targeted for ubiquitination and followed proteasomal degradation like I $\kappa \mathrm{B}(67)$. However, once phosphorylated by IKK $\alpha$, $\beta$-catenin abundance increases. IKK $\alpha$ could directly phosphorylate $\beta$-catenin at Ser33 to stabilize $\beta$-catenin expression and modulate function of Wnt/ $\beta$-catenin signaling, which stimulates the pro-proliferative cyclin D1 promoter. Knockdown of IKK $\alpha$ leads to downregulation of $\beta$-catenin expression, therefore results in multiple myeloma cell growth inhibition (68).

The observation of IKK $\alpha$ in the nucleus provides possibilities for its novel functions, the related substrates direct various mechanisms in inflammation and cancers. When it translocates into the nucleus, IKK $\alpha$ phosphorylates Ser2410 of SMRT (silencing mediator of retinoic acid and thyroid hormone receptor) and releases this repressor protein from Notch 1 target gene, resulting in increased expression of Notch-dependent genes like herp $2 /$ hrt 1 and hes 1 , and the malignant transformation in colorectal cancer (69). Additionally, IKK $\alpha$ phosphorylates FOXA2 at Ser107/Ser111 in the nucleus to suppress its transactivation activity, leading to decreased expression of downstream targets such as NUMB, which act as Notch 1 inhibitors, therefore help the proliferation of hepatocytes and tumorigenesis in hepatocellular carcinoma (70). p27/Kip1, the cyclin-dependent kinase inhibitor and a negative regulator during cell cycle G1-S transition, which has been reported involved in ErbB2induced mammary tumorigenesis, is also phosphorylated by IKK $\alpha$ at Ser12, Thr42, Ser175, Ser178 and Ser183. Intriguingly, the adjacent sequences are similar to known IKK phosphorylation sites and seem to be conserved in mammals. Phosphorylated p27 goes through nuclear export or exclusion, thus loses the suppressing effect on tumor-initiating cells (71). Actually according to current literature, the role of IKK $\alpha$ in tumor development differs within tissues. In colorectal, hepatocellular, breast and prostate cancers, IKK $\alpha$ acts as promoter of tumorigenesis, but inversely to be tumor suppressor in skin cancer and lung carcinomas (72).

Herein, dissection of the crosstalk between IKK $\alpha /$ IKK $\beta$ and such tumor-related proteins provide new understanding of inflammation-related tumorigenesis. In all, inhibitors of IKK $\alpha /$ IKK $\beta$, AKT and ERK may work to reactivate tumor suppressors like FOXOs, TSC and p53, therefore developing therapeutic agents of the above multitarget may provide an efficient strategy for antitumor treatment.

\section{IKK $\alpha$ and IKK $\beta$ play essential roles in immune response and immunological disorders}

Type 1 interferon (IFNs) are a group of polypeptides constituting the first line of host immune defense, and infection by virus or double-strand RNA (dsRNA) leads to the activation of transcription factors of IRF family IRF3, IRF5 and IRF7, key activators of IFN genes and chemokine genes (73). IRF proteins consist of two major domains, a C-terminal activating domain along with an N-terminal DNA binding domain. The C-terminal autoinhibitory region is responsible for their activation in the cytoplasm, phosphorylation of critical serine and threonine residues stimulates the dimerization and nuclear transport, as well as the initiation of transcription (74).

IKK $\alpha$ has been reported critically involved in the TLRMyD88-TRAF6 pathway-induced IFN production, and IRF5 and IRF7 are direct substrates of IKK $\alpha$ (Figure 2). Intriguingly, phosphorylation of IRF5 by IKK $\alpha$ attenuates transcriptional activation of IFNs (75), while in contrast, phosphorylated IRF7 serves as a positive regulator to manipulate TLR-induced IFN production (76). Multiple C-terminal serine residues of IRF5 are suggested to be phosphorylated by IKK $\alpha$, phosphorylation then inhibits K63 linked ubiquitination of IRF5 and suppresses transcriptional activation of IFN genes (77). On the other hand, activation of ifn $\alpha$ gene expression via IKK $\alpha$ phosphorylating IRF7 suggests that, IKK $\alpha$ could be a potential therapeutic target for certain autoimmune disorders whose IFN- $\alpha$ production is elevated, such as systemic lupus erythematosus (76).

In early-phase allergic response, IKK $\beta$ participates in and regulates immune response independent of NF$\kappa \mathrm{B}$ activation. Immunoglobulin E-activated IKK $\beta$ phosphorylates substrate SNAP23 at Ser120 and Ser95, which in turn initiates membrane fusion and exocytosis of 
the SNARE complex of SNAP23/syntaxin4/VAMP2 for degranulation of mast cells $(78,79)$. The following release of LTC4, histamine and multiple biochemical mediators all triggers allergic inflammation which may lead to allergic diseases, for instance asthma, atopic rhinitis and dermatitis. NF- $\kappa \mathrm{B}$ activation is not responsible for mast cell degranulation, however, NF- $\kappa \mathrm{B}$-dependent IKK $\beta$ kinase activity induces proinflammatory cytokine secretion which in turn promotes late-phase allergic reactions (79). All of the above findings indicate the central regulator role IKK $\beta$ plays in allergic reactions.

\section{IKK $\alpha$ and IKK $\beta$ are double-edged swords in autophagy} In response to sub-lethal stress like cellular starvation, cells may utilize autophagy, a fundamental cellular process contributing to numbers of physiological functions in eukaryotic cells, to survive from nutrient depletion and maintain basal homeostasis (80). IKK is known to mediate amino acid starvation-induced autophagy via a mechanism independent of NF- $\kappa \mathrm{B}$ by phosphorylating the phosphatidylinositol 3-kinase (PI3K) regulatory subunit p85 (Figure 2). When suffering nutrient deprivation, IKK phosphorylates p85 Ser690 at the conserved Srchomology 2 (SH2) domain, which results in reduced SH2phosphotyrosine interaction and subsequent blocking of Akt and mTOR signaling. The inhibition of mTORC1 is reported conducive to the initiation of autophagy (81). Another research suggests that c-Jun-N-terminal kinase 1 and AMP-activated protein kinase are also IKK substrates and phosphorylation on their specific serine/threonine residues could mediate starvation-induced autophagy. Interestingly, this pathway requires mTOR inhibition as well (82). Yet, studies of PTEN-inactive prostate cancer cells demonstrate that IKK $\alpha$ suppresses autophagy via mediating mTOR activation (83). Meanwhile, starvation also upregulates anti-apoptotic gene expression like Birc3 through activation of the NF- $\kappa$ B signaling (84).

Altogether, these studies show the dual opposite roles of IKK against cellular stress through separate pathways: on the one hand, it could initiate or suppress autophagy in the absence of NF- $\kappa B$; on the other hand, IKK regulates anti-apoptotic gene transcription in a NF- $\kappa \mathrm{B}$-dependent manner.

\section{IKKs mediate insulin resistance in diabetes}

Insulin resistance contributes importantly to type 2 diabetes mellitus, while many related factors like free fatty acids or TNF $\alpha$, are also activators of IKK complex (85). Thus there rises the crosstalk between metabolism and inflammatory signaling in the development of insulin resistance. IKK complex phosphorylates Ser312 on insulin receptor substrate 1 (IRS1), thereby blocking out the IRS1 ability (86) (Figure 2). As we know, the metabolic actions of insulin are predominantly mediated by signaling involving the IRS family proteins (87). Furthermore, Ser307 phosphorylation of rat IRS1 has been reported to inhibit insulin stimulation of the MAPK or the PI3K cascades, suggesting an equivalent function of human IRS1 Ser312 phosphorylation (88). Besides, the probable existence of extra IKK phosphorylation sites on the IRS family proteins implies that they may represent a novel group of substrates for IKK kinases (89).

Furthermore, insulin receptor (IR) is also a direct substrate of TBK1. It has been shown that TBK1 can phosphorylate IR on Ser994 to impair the activity of the receptor, and may negatively regulate insulin signaling and result in insulin resistance (90).

Taken together, these findings place the inhibition of such kinases as promising targets in the treatment of type 2 diabetes and related disorders.

\section{TBK1/IKKe in NF- $\mathrm{NB}$ regulation}

Like traditional IKK $\alpha / \beta / \gamma$, IKK $\varepsilon$ can be induced in response to proinflammatory cytokines such as TNF $\alpha$, LPS, and phorbol myristate acetate, and Ser172 of IKKe is essential for phosphorylation (21). However, IKKe has different substrate specificity and kinetics from IKK $\alpha$ and IKK $\beta$ (91). Activated IKK $\varepsilon$ specifically phosphorylates Ser36 of I $\kappa \mathrm{B} \alpha$, but not Ser32, therefore it seems that

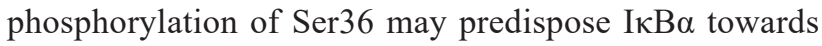
Ser32 phosphorylation and subsequent degradation (21) (Figure 3). Mouse embryonic fibroblasts lacking IKKe or TBK1 exhibit normal NF- $\mathrm{BB}$ activity while they are incapable of inducing numbers of well-characterized NF- $\kappa \mathrm{B}$ target genes, whereas phosphorylation of p65 is proposed to explain these defects (92). Quite a few serine residues on p65 have been identified as phosphorylation sites and are targeted by distinct signaling pathways. Besides IKK $\alpha$ and IKK $\beta$, upon IL- 1 and T cell costimulation, IKKe also phosphorylates Ser468 and 536 of p65 to enhance its transcriptional activity. Ser536phosphorylated p65 is mainly found in the cytosol while Ser468 phosphorylation occurs predominantly in the nucleus $(93,94)$. A series of $\mathrm{NF}-\kappa \mathrm{B}$ regulated genes are largely dependent on IKK $\varepsilon$-mediated p65 phosphorylation, such as Il6, Vcam1, IP10, Saa3 and Cox2 (95). In addition, as an oncogene expressed in numerous types of cancer cells, IKKe controls the basal/constitutive p65 Ser536 phosphorylation and plays vital roles in cancer cell survival and proliferation (96).

\section{TBK1 and IKKE initiate tumorigenesis through phosphorylating Akt and induce transformation}

As the crucial downstream effector in PI3K pathway, Akt is essential in normal cellular physiology like proliferation, survival and growth, while pathological Akt activation contributes to many human cancers (97). A common model for Akt activation is that, phosphatidyl inositol-dependent kinase-1 and mTORC2 separately phosphorylate Akt on its activation loop Thr308 and hydrophobic motif Ser473 $(98,99)$. Here is a report showing that IKK $\varepsilon / \mathrm{TBK} 1$ is sufficient to phosphorylate both the activation loop and hydrophobic motif of Akt protein, and such activation can be induced by several growth factors, for instance platelet derived growth factor and epidermal growth factor (Figure 3). Additionally, $\mathrm{PI} 3 \mathrm{~K}$ signaling is required in this activation process although the IKKe/TBK1 activity is irrelevant to PI3K. 


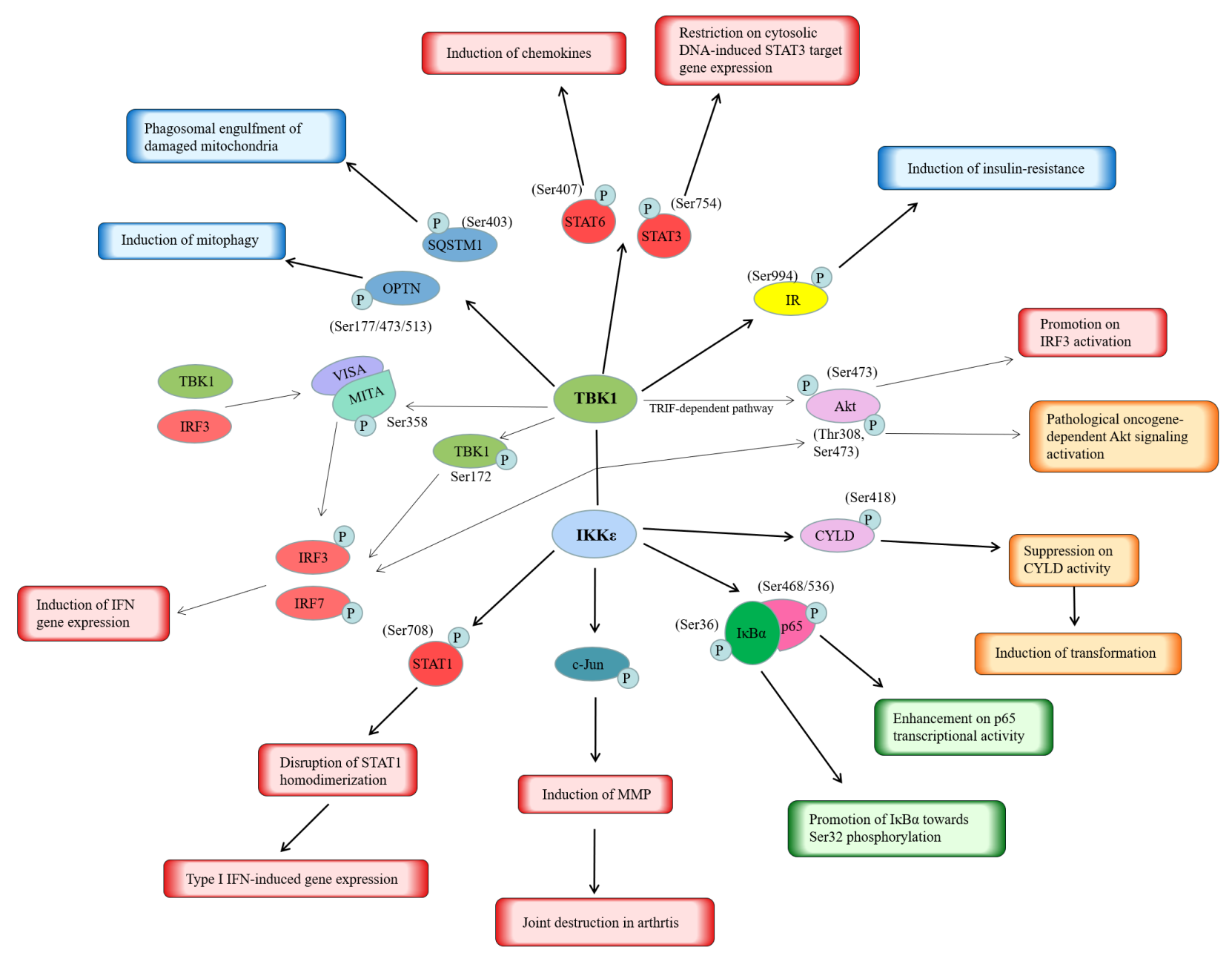

Figure 3. The substrates of TBK1 and IKK $\varepsilon$ and the related functions. Activated IKKE and TANK-binding kinase 1 (TBK1) modify numerous substrates and function in many biological processes, such as immune response, cell proliferation and survival, insulin signaling, and autophagy, some of which result in immune disorders and cancers.

This phosphorylation is required to sustain pathological oncogene-dependent Akt signaling and contributes to primary tumor initiation and development (100). Intriguingly, Akt activation diverges from PI3K in the TRIF (TIR domain-containing adaptor inducing IFN- $\beta$ )dependent signaling, a cascade responsible for TLR4dependent IRF3 activation. In response to ligand stimulation, TBK1 cooperates with Akt to enhance Ser473 phosphorylation of Akt. In this context, Akt serves as a downstream component of the TRIF/TBK1 pathway to promote activation of IRF3 $(101,102)$. These discoveries indicate that pathological activation of TBK1 or IKKE promotes tumorigenesis by activating AKT, at least partially so.

Ubiquitin carboxyl-terminal hydrolase CYLD, a member of the deubiquitinating enzyme family specific for K63linked poly-ubiquitins, acts as a tumor suppressor in familial cylindromatosis (103). CYLD suppresses a large number of inflammatory mediators including TRAF2, TRAF6, and NEMO by removing their poly-ubiquitins (104). However, this disruption disappears once CYLD Ser418 phosphorylation is induced by activated IKKs in a NEMO-dependent way, and the efficiency is comparable to the I $\mathrm{B}$ phosphorylation by IKKs. Phosphorylated CYLD then inactivates its TRAF2 de-ubiquitination activity, promoting expression (105). Not long after, IKK $\varepsilon$ is also identified to phosphorylate CYLD on Ser418 and seems much more efficient than IKK $\alpha$ or IKK $\beta$. Same as IKKs, IKK $\varepsilon$-mediated phosphorylation of CYLD suppresses CYLD activity and increases NF- $\kappa B$ activation, and moreover, is necessary for IKK $\varepsilon$ to fully induce transformation (106). These findings connect the oncogene IKK $\varepsilon$ and the tumor suppressor CYLD, spell out the regulation of $\mathrm{NF}-\kappa \mathrm{B}$ on cell transformation and lead to an increased understanding of how they function in oncogenesis.

\section{TBK1 and IKKe regulate innate immunity by regulating IRF3 and IRF7 activity}

In addition to IKK $\alpha$, IKKe/TBK1 is also involved in IFN- $\beta$ induction through activation of IRF3 and IRF7 by direct phosphorylation on their C-terminal regulatory domain (107) (Figure 3). In the first step, TLR3 or TLR4 ligands like LPS and dsRNA recruit TRIF, which then connects to the TBK1/IKKe complex through TRAF3 for subsequent IRF3 phosphorylation (28). However, TBK1/ 
IKK $\varepsilon$ do not seem to be required in TLR7-, TLR8- or TLR9-related IRF7 phosphorylation (108). There are three clusters of phospho-acceptor sites on IRF3, Ser385/ Ser386 (cluster1), Ser396/Ser398 (cluster2), and Ser402/ Ser404/Ser405 (cluster3). It has been shown that cluster2 and cluster 3 are the first sites targeted by IKK $\varepsilon$ or TBK1 and then prime the targeting of cluster 1 , sequential phosphorylation is indispensable for the complete unfolding and full activation of IRF3 (109).

Besides TLR-dependent pathway, innate immune responses to viral pathogens or dsDNA separately rely on the melanoma differentiation-associated gene 5 (MDA5) and retinoid acid-inducible gene I (RIG-I) or DNAdependent activator of IFN-regulatory factors to trigger TBK1/IKK $\varepsilon$-mediated IRF3 and IRF7 phosphorylation and IFN gene expression (110). The two caspase recruitment domains (CARDs) on N-terminal of both MDA5 and RIG-I are required for signal transmitting to the downstream CARD-containing adaptor protein VISA (111), while VISA has been demonstrated to be responsible for the activation of IRF3 (112). Researchers designate an uncharacterized protein as MITA, who is phosphorylated on Ser358 by TBK1 during viral infection, TBK1 and IRF3 are then recruited to VISA through this activated scaffold protein. Therefore, TBK1-mediated phosphorylation of MITA is closely associated to virustriggered IRF3 activation (113). Intriguingly during dsDNA stimulation, endoplasmic reticulum-resident adaptor protein STING acts as another scaffold to recruit IRF3 for TBK1-mediated IRF3 activation (114).

In addition to extra substrates, crystal structure reveals a potential trans-autoactivation domain of TBK1 existing to support the fully autoactivation and maintain the normal function of TBK1 (115). In this situation, glycogen synthase kinase $3 \beta$ (GSK3 $\beta$ ) physically associated with TBK1, promoting the prerequisite dimerization or oligomerization of TBK1 for its Ser172 autophosphorylation, and leading to virus-triggered induction of IRF3, IFN- $\beta$ as well as antiviral response (116).

\section{TBK1 and IKKe-mediating STAT family phosphorylation crosslinks innate immunity and oncogenic pathways}

Type I IFNs, like many other cytokines, utilize the canonical JAK (Janus kinase) - STAT (signal transducers and activators of transcription) pathway to function in innate immunity (117). Phosphorylation of STAT1 at Ser708 by IKKe has been reported to disrupt STAT1 homodimerization, thereby enlarging the STAT1 pool for optimally assembling the crucial IFN-I transcription factor complex ISGF3, which subsequently results in the shift of GAS-driven type I IFN-induced gene expression to ISREdriven gene expression (Figure 3). This well-characterized process implies a role of IKK $\varepsilon$ in manipulating and balancing the IFN-I and IFN-II signaling pathways (118).

In addition, viral infections or cytosolic nucleic acids activate TBK1 to phosphorylate STAT6 at Ser407 or STAT3 at Ser754 in the transactivation domain, in a
STING-dependent manner. However, phosphorylated STAT6 induces chemokines for recruiting immune cells to defend against viral infection, such as CCL2, CCL20 and CCL26, whereas phosphorylated STAT3 restricts its activity to respond to cytosolic DNA for target gene expression $(119,120)$. Given the well-established roles of STAT3 and STING in carcinogenesis and disease progression, these findings may shed light on the crosstalk between STAT-driven oncogenic signaling cascade and innate immune responses.

\section{Phosphorylation of receptors by TBK1 contributes to selective autophagy}

Canonical IKK members have been previously shown to control autophagy initiation, here it is reported that autophagic process is controlled by TBK1 (121). Autophagy receptors such as SQSTM1 (p62), optineurin (OPTN), NDP52 and NBR1, are involved in selective autophagy, whose function is to link ubiquitin cargoes to autophagosomal membranes as the ubiquitin signaling decoders (122). As the most closely related protein to NEMO, OPTN was identified as a substrate of TBK1 in two-hybrid screens (123) (Figure 3). TBK1 binds and phosphorylates OPTN on Ser177, Ser473 and Ser513. Ser177 phosphorylation in OPTN is known for ATG8 recruitment, while the dual phosphorylation of Ser473 and Ser513 activates polyubiquitin chain binding of OPTN, followed by the facilitated activation of TBK1 in vivo, as well as OPTN retention on damaged mitochondria, and mitophagy $(124,125)$. Within a positive feedback loop, ubiquitinated Salmonella or mitochondria recruits TBK1 and facilitates its clustering and activation, which in turn phosphorylates OPTN (126).

Earlier studies have suggested that SQSTM1 is recruited to mitochondria clusters to induce autophagosome of damaged mitochondria (127). However, subsequent observations have indicated that SQSTM1 mediates the aggregation of dysfunctional mitochondria through polymerization, but not for itself (128). Activated TBK1 phosphorylates SQSTM1 on Ser403, which is indispensable for its role in autophagic clearance and autophagosomal engulfment of polyubiquitinated mitochondria (129). Altogether, TBK1-mediated phosphorylation of autophagy receptors profoundly affects the regulation of TBK1 and selective autophagy pathway via a self-reinforcing positive feedback mechanism.

Due to its essential contribution to the suppression of excessive reactive oxygen species accumulation(130) and its participation in cellular death and senescence(131), autophagy is assumed to be a potent tumor-suppressive mechanism. It is worth further investigation that whether the IKK-dependent autophagy contributes to their tumorsuppressive function.

\section{IKK $\varepsilon$ phosphorylates c-Jun to promote rheumatoid arthritis (RA)}

Rheumatoid arthritis (RA) is a chronic autoimmune disease which is closely related to the transcription factor 
NF- $\mathrm{B}$ (132). Surprisingly in fibroblast-like synoviocytes, c-Jun, a well-known regulator of matrix metalloproteinase (MMP) gene and activator of antiviral program (133), is identified as an efficient downstream target of IKKe (Figure 3). Upon stimulation of IL-1 and TNF $\alpha$, IKK $\varepsilon$ immunoprecipitates rapidly and efficiently phosphorylate c-Jun, although the specific residues are still missing. The induction of MMP is significantly increased, which plays a key role in joint destruction in arthrtis (134). These intriguing data suggest IKK $\varepsilon$ as a novel and potential therapeutic target in RA which links innate immunity, extracellular matrix destruction and cell recruitment.

\section{Conclusions and perspectives}

During the past three decades, research has gained great insight into the composition, activation, regulation and function of IKK members. The substrate spectrum of the IKKs exhibits far more than I $\kappa$ Bs and precursors, which includes some other components in the NF- $\kappa \mathrm{B}$ pathway and lots of extraneous proteins. While some excellent reviews focus on the activation and $\mathrm{NF}-\kappa \mathrm{B}$-independent functions of IKK members (135), and non-conventional roles of specific $\mathrm{NF}-\kappa \mathrm{B}$ elements and the connection with other signaling pathways (84), in this review we have revised some of the well characterized substrates regulated by IKKs and emphasized the exact phosphorylation sites and modification patterns as well as their related function in vivo.

Despite the increasing identification of IKK-related substrates with diverse biological functions mediated by their phosphorylation, there still remains an important unanswered question: how substrate specificity is exactly achieved. Hoffmann et al. have demonstrated that NEMO functions as a scaffold targeting IKK to I $\mathrm{BBs}$ specifically and reduces alternate substrate phosphorylation within the inflammatory pathway (136). It offers us the idea that there must exist other scaffolds that may target IKKs towards alternate substrates and functions. Such scaffolds may totally replace NEMO and represent a new pathway determinant, or they may connect to IKKs together with NEMO and provide the crosstalk of inflammation with the other pleiotropic functions of IKKs. On the other hand, proteomic and immunofluorescence studies imply that TBK1 may use localization as a key specificity determinant, since its interactions with various adaptor proteins lead to different subcellular localizations and direct TBK1 towards diverse downstream pathways (137). To this end, co-recruitment and co-localization of kinases and substrates both offer to drive IKK substrate selection, and understanding the mechanism of IKKs' substrate specificity in different signaling axes may be critical for targeting IKKs in numerous diseases.

As our understanding of IKKs in mammalian physiology and pathophysiology is continuously developing, the IKK members involved human diseases like cancers and immune disorders also increase, however actually the pharmacological intervention targeting IKKs is still limited in clinical application. IKK $\beta$ has been by far the major focus in developing selective inhibitors for therapy, and in fact inhibitors targeting IKK $\beta$ and NEMO have already been developed and put into preclinical studies, and inhibitors of TBK1 and IKK $\varepsilon$ also have been tested in several cell studies and animal models. However, due to the unwanted toxicity by interfering with systemic NF$\kappa \mathrm{B}$ activities, none of them receive clinical approval (138), which get us thinking what kind of IKK inhibitors could make ideal drugs. The most important point is that it should only specifically intervene the given diseases or cancers with minimal effects on fundamental NF- $\mathrm{B}$ functions in normal tissues. The numerous roles of IKKs in multiple pathways bring most of the complexity, because in different cells requiring NF- $\kappa \mathrm{B}$ with diverse purposes, the outcomes vary. Secondly, the wanted inhibitors should be able to specifically and efficiently recognize its targeted IKK member, since the catalytic domains of four IKKs have significant similarity. Also, the dose, delivery method and delivery schedule which are related to clinical trials should all be taken into consideration. As for designing small molecule inhibitors, the structural differences on catalytic domains of IKKs and the exact phosphorylation sites of non-overlapping substrates targeted by different IKK members which are highlighted in this review may give a clue. Moreover, through comparing the effects of kinase inhibitors versus small molecule inhibitors, we could make it clear which functions are kinase-dependent, and the others perhaps are kinase-independent like scaffolding roles.

Regardless of the difficulties in the development of effective inhibitors targeting IKK members, the notable roles of IKKs in multiple signaling pathways and pathological processes we have presented in this review still indicate that these proteins are potential therapeutic targets for various diseases and malignancies. Additionally, with the developing structural and biophysical techniques, combined with the newly arisen single-cell computational studies, the latest research may shed light on the unsolved problems mentioned above.

\section{Conflict of interest}

The authors declare that they have no conflict of interest.

\section{References}

1. Baeuerle PA, Baltimore D. NF-KB: ten years after. Cell. 1996;87(1):13-20.

2. Ghosh G, Wang VYF, Huang DB, Fusco A. NF-kB regulation: lessons from structures. Immunol Rev. 2012;246(1):36-58.

3. Gilmore TD. 2008 [Available from: www.NF-kB.org.

4. Hayden MS, Ghosh S. Shared principles in NF-KB signaling. Cell. 2008;132(3):344-62.

5. Hayden MS, Ghosh S. NF-kB in immunobiology. Cell Res. 2011;21(2):223-44.

6. Perkins ND. Integrating cell-signalling pathways with NF-KB and IKK function. Nat Rev Mol Cell Biol. 2007;8(1):49-62.

7. Ghosh S, May MJ, Kopp EB. NF-KB and Rel proteins: evolutionarily conserved mediators of immune responses. Annu Rev Immunol. 1998;16(1):225-60.

8. Karin M, Ben-Neriah Y. Phosphorylation meets ubiquitination: the control of NF-KB activity. Annu Rev Immunol. 2000;18(1):621-63. 
9. Régnier $\mathrm{CH}$, Song HY, Gao X, Goeddel DV, Cao Z, Rothe $M$. Identification and characterization of an IKB kinase. Cell. 1997;90(2):373-83.

10. DiDonato JA, Hayakawa M, Rothwarf DM, Zandi E, Karin M. A cytokine-responsive IKB kinase that activates the transcription factor NF-kB. Nature. 1997;388(6642):548-54.

11. Woronicz JD, Gao X, Cao Z, Rothe M, Goeddel DV. IkB kinase-b: NF-kB activation and complex formation with IkB kinase-a and NIK. Science-AAAS-Weekly Paper Edition. 1997;278(5339):866-9.

12. Zandi E, Rothwarf DM, Delhase M, Hayakawa M, Karin M The IKB kinase complex (IKK) contains two kinase subunits, $\mathrm{IKK} \alpha$ and IKK $\beta$, necessary for IKB phosphorylation and NFKB activation. Cell. 1997;91(2):243-52.

13. Mercurio F, Zhu H, Murray BW, Shevchenko A, Bennet $\mathrm{BL}, \mathrm{Wu} \mathrm{Li}$ J, et al. IKK-1 and IKK-2: cytokine-activated IKB kinases essential for NF-KB activation. Science. 1997;278(5339):860-6

14. Ling L, Cao Z, Goeddel DV. NF-KB-inducing kinase activates IKK- $\alpha$ by phosphorylation of Ser-176. Proc Natl Acad Sci USA. 1998;95(7):3792-7.

15. May MJ, Larsen SE, Shim JH, Madge LA, Ghosh S. A nove ubiquitin-like domain in IKB kinase $\beta$ is required for functional activity of the kinase. J Biol Chem. 2004;279(44):45528-39.

16. Sil AK, Maeda S, Sano Y, Roop DR, Karin M. IKB kinaseacts in the epidermis to control skeletal and craniofacial morphogenesis. Nature. 2004;428(6983):660-4

17. Scheidereit C. I к B kinase complexes: gateways to NF-KB activation and transcription. Oncogene. 2006;25(51):6685-705.

18. Peters RT, Maniatis T. A new family of IKK-related kinases may function as I kappa B kinase kinases. Biochim Biophys Acta. 2001;1471(2):M57-62.

19. Tojima Y, Fujimoto A, Delhase M, Chen Y, Hatakeyama S, Nakayama K-i, et al. NAK is an IKB kinase-activating kinase. Nature. 2000;404(6779):778-82.

20. Pomerantz JL, Baltimore D. NF-KB activation by a signaling complex containing TRAF2, TANK and TBK1, a novel IKK related kinase. EMBO J. 1999;18(23):6694-704.

21. Shimada T, Kawai T, Takeda K, Matsumoto M, Inoue $\mathrm{J}$-i, Tatsumi $\mathrm{Y}$, et al. IKK-i, a novel lipopolysaccharideinducible kinase that is related to IKB kinases. Int Immunol. 1999;11(8):1357-62.

22. Larabi A, Devos JM, Ng S-L, Nanao MH, Round A, Maniatis $\mathrm{T}$, et al. Crystal structure and mechanism of activation of TANK-binding kinase 1. Cell Rep. 2013;3(3):734-46.

23. Sasai M, Shingai M, Funami K, Yoneyama M, Fujita T, Matsumoto $M$, et al. NAK-associated protein 1 participates in both the TLR3 and the cytoplasmic pathways in type I IFN induction. J Immunol. 2006;177(12):8676-83.

24. Aguilera C, Hoya-Arias R, Haegeman G, Espinosa L, Bigas A. Recruitment of IKBa to the hes1 promoter is associated with transcriptional repression. Proc Natl Acad Sci USA. 2004;101(47):16537-42.

25. Kishore N, Huynh QK, Mathialagan S, Hall T, Rouw S, Creely $D$, et al. IKK-i and TBK-1 are enzymatically distinct from the homologous enzyme IKK-2 comparative analysis of recombinant human IKK-i, TBK-1, AND IKK-2. J Biol Chem. 2002;277(16):13840-7.

26. Senftleben U, Cao Y, Xiao G, Greten FR, Krähn G, Bonizzi G, et al. Activation by IKKa of a second, evolutionary conserved, NF-KB signaling pathway. Science. 2001;293(5534):1495-9.

27. Bonizzi G, Karin M. The two NF-kB activation pathways and their role in innate and adaptive immunity. Trends Immunol. 2004;25(6):280-8.

28. Fitzgerald KA, McWhirter SM, Faia KL, Rowe DC, Latz E, Golenbock DT, et al. IKKE and TBK1 are essential components of the IRF3 signaling pathway. Nat Immunol. 2003;4(5):491-6.

29. Hemmi H, Takeuchi O, Sato S, Yamamoto M, Kaisho T, Sanjo $\mathrm{H}$, et al. The roles of two IKB kinase-related kinases in lipopolysaccharide and double stranded RNA signaling and viral infection. J Exp Med. 2004;199(12):1641-50.

30. Sharma S, Grandvaux N, Zhou G-P, Lin R, Hiscott J. Triggering the interferon antiviral response through an IKKrelated pathway. Science. 2003;300(5622):1148-51.

31. Hasan M, Yan N. Therapeutic potential of targeting TBK1 in autoimmune diseases and interferonopathies. Pharmacol Res. 2016;111:336-42.

32. Rogers S, Wells R, Rechsteiner M. Amino acid sequences common to rapidly degraded proteins: the PEST hypothesis. Science. 1986;234(4774):364-8.

33. Hayden MS, Ghosh S. Signaling to NF-kB. Genes Dev. 2004;18(18):2195-224.

34. Kanarek N, Ben-Neriah Y. Regulation of NF-kB by ubiquitination and degradation of the IKBs. Immunol Rev. 2012;246(1):77-94.

35. Yaron A, Hatzubai A, Davis M, Lavon I, Amit S, Manning AM, et al. Identification of the receptor component of the IKBaubiquitin ligase. Nature. 1998;396(6711):590-4.

36. Mathes E, O'dea EL, Hoffmann A, Ghosh G. NF-kB dictates the degradation pathway of IKBa. EMBO J. 2008;27(9):1357-67.

37. Zandi E, Chen Y, Karin M. Direct phosphorylation of IKB by IKK $\alpha$ and IKK $\beta$ : discrimination between free and NF-KBbound substrate. Science. 1998;281(5381):1360-3.

38. Naumann M, Scheidereit C. Activation of NF-kappa B in vivo is regulated by multiple phosphorylations. EMBO J. 1994;13(19):4597-607.

39. Heissmeyer V, Krappmann D, Hatada EN, Scheidereit C. Shared pathways of IKB kinase-induced SCF $\beta$ TrCPmediated ubiquitination and degradation for the NF-kB precursor p105 and IKBa. Mol Cell Biol. 2001;21(4):1024-35.

40. Salmerón A, Janzen J, Soneji Y, Bump N, Kamens J, Allen $\mathrm{H}$, et al. Direct phosphorylation of NF-kB1 p105 by the IkB kinase complex on serine 927 is essential for signal-induced p105 proteolysis. J Biol Chem. 2001;276(25):22215-22.

41. Beinke S, Belich MP, Ley SC. The death domain of NF-kB1 p105 is essential for signal-induced p105 proteolysis. J Biol Chem. 2002;277(27):24162-8.

42. Lang V, Janzen J, Fischer GZ, Soneji Y, Beinke S, Salmeron $A$, et al. $\beta$ TrCP-mediated proteolysis of NF-KB1 p105 requires phosphorylation of p105 serines 927 and 932 . Mol Cell Biol. 2003;23(1):402-13.

43. Beinke $S$, Robinson M, Hugunin M, Ley $S$. Lipopolysaccharide activation of the TPL-2/MEK/extracellular signal-regulated kinase mitogen-activated protein kinase cascade is regulated by IKB kinase-induced proteolysis of NF-kB1 p105. Mol Cell Biol. 2004;24(21):9658-67.

44. Xiao G, Cvijic ME, Fong A, Harhaj EW, Uhlik MT, Waterfield $M$, et al. Retroviral oncoprotein Tax induces processing of NF-kB2/p100 in T cells: evidence for the involvement of IKKa. EMBO J. 2001;20(23):6805-15.

45. Sun SC. The noncanonical NF-KB pathway. Immunol Rev. 2012;246(1):125-40

46. Xiao G, Harhaj EW, Sun S-C. NF-kB-inducing kinase regulates the processing of NF-kB2 p100. Mol Cell. 2001;7(2):401-9.

47. Xiao G, Fong A, Sun S-C. Induction of p100 processing by NF-kappaB-inducing kinase involves docking IKKalpha to p100 and IKKalpha-mediated phosphorylation. J Biol Chem. 2004;279(29):30099-105.

48. Savinova OV, Hoffmann A, Ghosh G. The Nfkb1 and Nfkb2 proteins p105 and p100 function as the core of highmolecular-weight heterogeneous complexes. Mol Cell. 2009;34(5):591-602.

49. Tergaonkar V, Correa RG, Ikawa M, Verma IM. Distinct roles of IKB proteins in regulating constitutive NF-KB activity. Nat Cell Biol. 2005;7(9):921-3.

50. Neumann M, Naumann M. Beyond IKBs: alternative regulation of NF-KB activity. FASEB Jl. 2007;21(11):2642-54.

51. Sakurai $H$, Chiba $H$, Miyoshi $H$, Sugita T, Toriumi W. IKB kinases phosphorylate NF-kB p65 subunit on serine 536 in the transactivation domain. J Biol Chem. 1999;274(43):30353-6. 
52. Sakurai H, Suzuki S, Kawasaki N, Nakano H, Okazaki $\mathrm{T}$, Chino A, et al. Tumor necrosis factor- $\alpha$-induced IKK phosphorylation of NF-KB p65 on serine 536 is mediated through the TRAF2, TRAF5, and TAK1 signaling pathway. J Biol Chem. 2003;278(38):36916-23.

53. Yang F, Tang E, Guan K, Wang C-Y. IKK $\beta$ plays an essential role in the phosphorylation of RelA/p65 on serine 536 induced by lipopolysaccharide. J Immunol. 2003;170(11):5630-5

54. Mattioli I, Sebald A, Bucher C, Charles R-P, Nakano H, Doi T, et al. Transient and selective NF-kB p65 serine 536 phosphorylation induced by $T$ cell costimulation is mediated by IKB kinase $\beta$ and controls the kinetics of p65 nuclear import. J Immunol. 2004;172(10):6336-44.

55. Lawrence T, Bebien M, Liu GY, Nizet V, Karin M. IKKa limits macrophage NF-KB activation and contributes to the resolution of inflammation. Nature. 2005;434(7037):1138-43

56. Yamaoka S, Courtois G, Bessia C, Whiteside ST, Weil $\mathrm{R}$, Agou $\mathrm{F}$, et al. Complementation cloning of NEMO, a component of the IKB kinase complex essential for NF-KB activation. Cell. 1998;93(7):1231-40.

57. Carter RS, Pennington KN, Ungurait BJ, Ballard DW. In vivo identification of inducible phosphoacceptors in the IKKY/NEMO subunit of human IkB kinase. J Biol Chem. 2003;278(22):19642-8.

58. Palkowitsch L, Leidner J, Ghosh S, Marienfeld RB. Phosphorylation of serine 68 in the IKB kinase (IKK)-binding domain of NEMO interferes with the structure of the IKK complex and tumor necrosis factor- $\alpha$-induced NF-KB activity. J Biol Chem. 2008;283(1):76-86.

59. Xia Y, Padre RC, De Mendoza TH, Bottero V, Tergaonkar VB, Verma IM. Phosphorylation of p53 by IKB kinase 2 promotes its degradation by $\beta$-TrCP. Proc Natl Acad Sci USA. 2009;106(8):2629-34.

60. Kawauchi K, Araki K, Tobiume K, Tanaka N. p53 regulates glucose metabolism through an IKK-NF-KB pathway and inhibits cell transformation. Nat Cell Biol. 2008;10(5):611-8.

61. Murphy SH, Suzuki K, Downes M, Welch GL, De Jesus P, Miraglia LJ, et al. Tumor suppressor protein (p) 53 , is a regulator of NF-kB repression by the glucocorticoid receptor. Proc Natl Acad Sci USA. 2011;108(41):17117-22.

62. Paik J-H, Kollipara R, Chu G, Ji H, Xiao Y, Ding Z, et al. FoxOs are lineage-restricted redundant tumor suppressors and regulate endothelial cell homeostasis. Cell. 2007;128(2):309-23.

63. Hu MC-T, Lee D-F, Xia W, Golfman LS, Ou-Yang F, Yang J-Y, et al. IKB kinase promotes tumorigenesis through inhibition of forkhead FOXO3a. Cell. 2004;117(2):225-37.

64. Yang J-Y, Hung M-C. A new fork for clinical application: targeting forkhead transcription factors in cancer. Clin Cancer Res. 2009;15(3):752-7.

65. Lee D-F, Kuo H-P, Chen C-T, Hsu J-M, Chou C-K, Wei Y, et al. IKK $\beta$ suppression of TSC1 links inflammation and tumor angiogenesis via the mTOR pathway. Cell. 2007;130(3):440-55.

66. Doyon P, van Zuylen WJ, Servant MJ. Role of IkB kinase- $\beta$ in the growth-promoting effects of angiotensin II in vitro and in vivo. Arterioscler Thromb Vasc Biol. 2013;33(12):2850-7.

67. Lamberti C, Lin K-M, Yamamoto Y, Verma U, Verma IM Byers $S$, et al. Regulation of $\beta$-catenin function by the $1 \mathrm{kB}$ kinases. J Biol Chem. 2001;276(45):42276-86.

68. Albanese C, Wu K, D'Amico M, Jarrett C, Joyce D, Hughes $\mathrm{J}$, et al. IKKa regulates mitogenic signaling through transcriptional induction of cyclin D1 via Tcf. Mol Biol Cell. 2003;14(2):585-99.

69. Fernandez-Majada V, Aguilera C, Villanueva A, Vilardell F, Robert-Moreno A, Aytes A, et al. Nuclear IKK activity leads to dysregulated notch-dependent gene expression in colorectal cancer. Proc Natl Acad Sci USA. 2007;104(1):276-81.

70. Liu M, Lee D-F, Chen C-T, Yen C-J, Li L-Y, Lee H-J, et al, IKKa activation of NOTCH links tumorigenesis via FOXA2 suppression. Mol Cell. 2012;45(2):171-84.
71. Zhang W, Tan W, Wu X, Poustovoitov M, Strasner A, Li W, et al. A NIK-IKKa module expands ErbB2-induced tumorinitiating cells by stimulating nuclear export of p27/Kip1. Cancer cell. 2013;23(5):647-59.

72. Hinz M, Scheidereit C. The IKB kinase complex in NF-KB regulation and beyond. EMBO reports. 2014;15(1):46-61.

73. Iwamura T, Yoneyama M, Yamaguchi K, Suhara W, Mori W, Shiota $\mathrm{K}$, et al. Induction of IRF-3/-7 kinase and NF-KB in response to double-stranded RNA and virus infection: common and unique pathways. Genes Cells. 2001;6(4):375-88.

74. Chen W, Lam SS, Srinath H, Jiang Z, Correia JJ, Schiffer $\mathrm{CA}$, et al. Insights into interferon regulatory factor activation from the crystal structure of dimeric IRF5. Nat Struct Mol Biol. 2008;15(11):1213.

75. Balkhi MY, Fitzgerald KA, Pitha PM. IKKa negatively regulates IRF-5 function in a MyD88-TRAF6 pathway. Cell Signal. 2010;22(1):117-27.

76. Hoshino K, Sugiyama T, Matsumoto M, Tanaka T, Saito $\mathrm{M}$, Hemmi $\mathrm{H}$, et al. IкB kinase- $\alpha$ is critical for interferon- $\alpha$ production induced by Toll-like receptors 7 and 9 . Nature. 2006;440(7086):949-53.

77. Balkhi MY, Fitzgerald KA, Pitha PM. Functional regulation of MyD88-activated interferon regulatory factor 5 by K63-linked polyubiquitination. Mol Cell Biol. 2008;28(24):7296-308.

78. Jahn R, Südhof TC. Membrane fusion and exocytosis. Annu Rev Biochem. 1999;68(1):863-911

79. Suzuki K, Verma IM. Phosphorylation of SNAP-23 by IKB kinase 2 regulates mast cell degranulation. Cell. 2008;134(3):485-95.

80. Criollo A, Niso-Santano M, Malik SA, Michaud M, Morselli E, Mariño $G$, et al. Inhibition of autophagy by TAB2 and TAB3. EMBO Jl. 2011;30(24):4908-20

81. Comb WC, Hutti JE, Cogswell P, Cantley LC, Baldwin AS. p85a SH2 domain phosphorylation by IKK promotes feedback inhibition of PI3K and Akt in response to cellular starvation. Mol Cell. 2012;45(6):719-30.

82. Criollo A, Senovilla L, Authier H, Maiuri MC, Morselli E, Vitale I, et al. The IKK complex contributes to the induction of autophagy. EMBO J. 2010;29(3):619-31.

83. Dan HC, Adli M, Baldwin AS. Regulation of mammalian target of rapamycin activity in PTEN-inactive prostate cancer cells by IkB kinase $\alpha$. Cancer Res. 2007;67(13):6263-9.

84. Espinosa L, Margalef P, Bigas A. Non-conventional functions for NF-KB members: the dark side of NF-KB. Oncogene. 2015;34(18):2279-87

85. Peraldi $P$, Spiegelman B. TNF- $\alpha$ and insulin resistance: summary and future prospects. Mol Cell Biochem. 1998;182(1-2):169-75.

86. Gao Z, Hwang D, Bataille F, Lefevre M, York D, Quon $M J$, et al. Serine phosphorylation of insulin receptor substrate 1 by inhibitor KB kinase complex. J Biol Chem. 2002;277(50):48115-21.

87. Saltiel AR, Kahn CR. Insulin signalling and the regulation of glucose and lipid metabolism. Nature. 2001;414(6865):799806.

88. Cao H. Adipocytokines in obesity and metabolic disease. J Endocrinol. 2014;220(2):T47-T59.

89. Aguirre V, Werner ED, Giraud J, Lee YH, Shoelson SE, White MF. Phosphorylation of Ser307 in insulin receptor substrate-1 blocks interactions with the insulin receptor and inhibits insulin action. J Biol Chem. 2002;277(2):1531-7.

90. Munoz MC, Giani JF, Mayer MA, Toblli JE, Turyn D, Dominici FP. TANK-binding kinase 1 mediates phosphorylation of insulin receptor at serine residue 994: a potential link between inflammation and insulin resistance. J Endocrinol. 2009;201(2):185-97.

91. Kishore N, Sommers C, Mathialagan S, Guzova J, Yao M, Hauser S, et al. A selective IKK-2 inhibitor blocks NF-KBdependent gene expression in interleukin-1 $\beta$-stimulated synovial fibroblasts. J Biol Chem. 2003;278(35):32861-71.

92. Kravchenko VV, Mathison JC, Schwamborn K, Mercurio F, 
Ulevitch RJ. IKKi/IKKE plays a key role in integrating signals induced by pro-inflammatory stimuli. J Biol Chem. 2003;278(29):26612-9.

93. Buss H, Dörrie A, Schmitz ML, Hoffmann E, Resch K, Kracht M. Constitutive and interleukin-1-inducible phosphorylation of p65 NF-KB at serine 536 is mediated by multiple protein kinases including IKB kinase (IKK)- $\alpha$, IKK $\beta$, IKKE, TRAF family member-associated (TANK)-binding kinase 1 (TBK1), and an unknown kinase and couples p65 to TATA-binding protein-associated factor 1131 -mediated interleukin-8 transcription. J Biol Chem. 2004;279(53):55633-43.

94. Mattioli I, Geng H, Sebald A, Hodel M, Bucher C, Kracht M, et al. Inducible phosphorylation of NF-KB p65 at serine 468 by $\mathrm{T}$ cell costimulation is mediated by $\mathrm{IKK} \epsilon$. J Biol Chem. 2006;281(10):6175-83.

95. Moreno R, Sobotzik J-M, Schultz C, Schmitz ML. Specification of the NF-KB transcriptional response by $\mathrm{p} 65$ phosphorylation and TNF-induced nuclear translocation of IKKE. Nucleic Acids Res. 2010;38(18):6029-44.

96. Adli M, Baldwin AS. IKK-i/IKKe controls constitutive, cancer cell-associated NF-KB activity via regulation of Ser-536 p65/ RelA phosphorylation. J Biol Chem. 2006;281(37):26976-84.

97. Testa JR, Tsichlis PN. AKT signaling in normal and malignant cells. Oncogene. 2005;24(50):7391-3.

98. Alessi DR, James SR, Downes CP, Holmes AB, Gaffney PR, Reese CB, et al. Characterization of a 3-phosphoinositidedependent protein kinase which phosphorylates and activates protein kinase Ba. Curr Biol. 1997;7(4):261-9.

99. Sarbassov DD, Guertin DA, Ali SM, Sabatini DM Phosphorylation and regulation of Akt/PKB by the rictormTOR complex. Science. 2005;307(5712):1098-101.

100. Xie X, Zhang D, Zhao B, Lu M-K, You M, Condorelli G, et al. IKB kinase $\varepsilon$ and TANK-binding kinase 1 activate AKT by direct phosphorylation. Proc Natl Acad Sci USA 2011;108(16):6474-9.

101. Joung SM, Park Z-Y, Rani S, Takeuchi O, Akira S, Lee JY. Akt contributes to activation of the TRIF-dependent signaling pathways of TLRs by interacting with TANK-binding kinase 1. J Immunol. 2011;186(1):499-507.

102. Ou Y-H, Torres M, Ram R, Formstecher E, Roland C, Cheng $\mathrm{T}$, et al. TBK1 directly engages Akt/PKB survival signaling to support oncogenic transformation. Mol Cell. 2011;41(4):458-70.

103. Bignell GR, Warren W, Seal S, Takahashi M, Rapley E, Barfoot $\mathrm{R}$, et al. Identification of the familial cylindromatosis tumour-suppressor gene. Nat Genet. 2000;25(2):160-5.

104. Trompouki E, Hatzivassiliou E, Tsichritzis T, Farmer $\mathrm{H}$, Ashworth A, Mosialos G. CYLD is a deubiquitinating enzyme that negatively regulates NF-KB activation by TNFR family members. Nature. 2003;424(6950):793-6.

105. Hutti JE, Shen RR, Abbott DW, Zhou AY, Sprott KM, Asara JM, et al. Phosphorylation of the tumor suppressor CYLD by the breast cancer oncogene IKK $\varepsilon$ promotes cell transformation. Mol Cell. 2009;34(4):461-72.

106. Reiley W, Zhang M, Wu X, Granger E, Sun S-C Regulation of the deubiquitinating enzyme CYLD by IKB kinase gamma-dependent phosphorylation. Mol Cell Biol. 2005;25(10):3886-95.

107. Han K-J, Su X, Xu L-G, Bin L-H, Zhang J, Shu H-B. Mechanisms of the TRIF-induced interferon-stimulated response element and NF-KB activation and apoptosis pathways. J Biol Chem. 2004;279(15):15652-61.

108. Kawai T, Sato S, Ishii KJ, Coban C, Hemmi H, Yamamoto $\mathrm{M}$, et al. Interferon- $\alpha$ induction through Toll-like receptors involves a direct interaction of IRF7 with MyD88 and TRAF6. Nat Immunol. 2004;5(10):1061-8.

109. Clément J-F, Bibeau-Poirier A, Gravel S-P, Grandvaux N Bonneil É, Thibault $\mathrm{P}$, et al. Phosphorylation of IRF-3 on Ser 339 generates a hyperactive form of IRF-3 through regulation of dimerization and CBP association. J Virol. 2008;82(8):3984-96.

110. Chau T-L, Gioia R, Gatot J-S, Patrascu F, Carpentier I,
Chapelle J-P, et al. Are the IKKs and IKK-related kinases TBK1 and IKK- $\varepsilon$ similarly activated? Trends Biochem Sci. 2008;33(4):171-80.

111. Xu L-G, Wang Y-Y, Han K-J, Li L-Y, Zhai Z, Shu H-B. VISA is an adapter protein required for virus-triggered IFN- $\beta$ signaling. Mol Cell. 2005;19(6):727-40.

112. Sun $Q$, Sun L, Liu H-H, Chen X, Seth RB, Forman J, et al. The specific and essential role of MAVS in antiviral innate immune responses. Immunity. 2006;24(5):633-42.

113. Zhong B, Yang $Y$, Li S, Wang Y-Y, Li Y, Diao F, et al. The adaptor protein MITA links virus-sensing receptors to IRF3 transcription factor activation. Immunity. 2008;29(4):538-50.

114. Tanaka Y, Chen ZJ. STING specifies IRF3 phosphorylation by TBK1 in the cytosolic DNA signaling pathway. Sci Signal. 2012;5(214):ra20-ra.

115. Ma X, Helgason E, Phung QT, Quan CL, lyer RS, Lee MW, et al. Molecular basis of Tank-binding kinase 1 activation by transautophosphorylation. Proc Natl Acad Sci USA. 2012;109(24):9378-83.

116. Lei C-Q, Zhong B, Zhang Y, Zhang J, Wang S, Shu H-B. Glycogen synthase kinase $3 \beta$ regulates IRF3 transcription factor-mediated antiviral response via activation of the kinase TBK1. Immunity. 2010;33(6):878-89.

117. Levy DE, Darnell J. Stats: transcriptional control and biological impact. Nat Rev Mol Cell Biol. 2002;3(9):651-62.

118. Ng S-L, Friedman BA, Schmid S, Gertz J, Myers RM, Maniatis $T$. IKB kinase $\varepsilon$ (IKKE) regulates the balance between type I and type II interferon responses. Proc Natl Acad Sci USA. 2011;108(52):21170-5.

119. Hsia H-C, Hutti JE, Baldwin AS. Cytosolic DNA promotes signal transducer and activator of transcription 3 (STAT3) phosphorylation by TANK-binding kinase 1 (TBK1) to restrain STAT3 activity. J Biol Chem. 2017;292(13):5405-17.

120. Chen H, Sun H, You F, Sun W, Zhou X, Chen L, et al. Activation of STAT6 by STING is critical for antiviral innate immunity. Cell. 2011;147(2):436-46.

121. Pilli M, Arko-Mensah J, Ponpuak M, Roberts E, Master S, Mandell MA, et al. TBK-1 promotes autophagy-mediated antimicrobial defense by controlling autophagosome maturation. Immunity. 2012;37(2):223-34.

122. Stolz A, Ernst A, Dikic I. Cargo recognition and trafficking in selective autophagy. Nat Cell Biol. 2014;16(6):495-501.

123. Morton S, Hesson L, Peggie M, Cohen P. Enhanced binding of TBK1 by an optineurin mutant that causes a familial form of primary open angle glaucoma. FEBS Lett. 2008;582(6):997-1002.

124. Heo J-M, Ordureau A, Paulo JA, Rinehart J, Harper JW. The PINK1-PARKIN mitochondrial ubiquitylation pathway drives a program of OPTN/NDP52 recruitment and TBK1 activation to promote mitophagy. Mol Cell. 2015;60(1):7-20.

125. Richter B, Sliter DA, Herhaus L, Stolz A, Wang C, Beli $P$, et al. Phosphorylation of OPTN by TBK1 enhances its binding to Ub chains and promotes selective autophagy of damaged mitochondria. Proc Natl Acad Sci USA. 2016;113(15):4039-44.

126. Wild $\mathrm{P}$, Farhan $\mathrm{H}$, McEwan DG, Wagner S, Rogov VV, Brady NR, et al. Phosphorylation of the autophagy receptor optineurin restricts Salmonella growth. Science. 2011;333(6039):228-33.

127. Geisler S, Holmström KM, Skujat D, Fiesel FC, Rothfuss $\mathrm{OC}$, Kahle PJ, et al. PINK1/Parkin-mediated mitophagy is dependent on VDAC1 and p62/SQSTM1. Nat Cell Biol. 2010;12(2):119-31.

128. Narendra D, Kane LA, Hauser DN, Fearnley IM, Youle RJ. p62/SQSTM1 is required for Parkin-induced mitochondrial clustering but not mitophagy; VDAC1 is dispensable for both. Autophagy. 2010;6(8):1090-106.

129. Matsumoto G, Shimogori T, Hattori N, Nukina N. TBK1 controls autophagosomal engulfment of polyubiquitinated mitochondria through p62/SQSTM1 phosphorylation. Hum Mol Genet. 2015;24(15):4429-42. 
130. Mathew R, Karp CM, Beaudoin B, Vuong N, Chen G, Chen $\mathrm{H}-\mathrm{Y}$, et al. Autophagy suppresses tumorigenesis through elimination of p62. Cell. 2009;137(6):1062-75.

131. Young AR, Narita M, Ferreira M, Kirschner K, Sadaie M, Darot JF, et al. Autophagy mediates the mitotic senescence transition. Genes Dev. 2009;23(7):798-803.

132. Li $Q$, Verma IM. NF-kB regulation in the immune system. Nat Rev Immunol. 2002;2(10):725-34.

133. Malmgaard L. Induction and regulation of IFNs during viral infections. J Interf Cytok Res. 2004;24(8):439-54.

134. Sweeney SE, Hammaker D, Boyle DL, Firestein GS. Regulation of c-Jun phosphorylation by the IKB kinase- $\varepsilon$ complex in fibroblast-like synoviocytes. J Immunol. 2005;174(10):6424-30.
135. Liu F, Xia Y, Parker AS, Verma IM. IKK biology. Immunol Rev. 2012;246(1):239-53.

136. Schröfelbauer B, Polley S, Behar M, Ghosh G, Hoffmann A. NEMO ensures signaling specificity of the pleiotropic IKK $\beta$ by directing its kinase activity toward IKBa. Mol Cell. 2012;47(1):111-21.

137. Helgason E, Phung QT, Dueber EC. Recent insights into the complexity of Tank-binding kinase 1 signaling networks: the emerging role of cellular localization in the activation and substrate specificity of TBK1. FEBS Lett. 2013;587(8):1230-7.

138. Tornatore L, Sandomenico A, Raimondo D, Low C, Rocci A, Tralau-Stewart $C$, et al. Cancer-selective targeting of the NF-KB survival pathway with GADD45 $\beta / M K K 7$ inhibitors. Cancer Cell. 2014;26(4):495-508. 